\title{
Stress Concentration Factor of A Two-Planar Double KT Tubular Joint due to In-Plane Bending Loading in Steel Offshore Structures
}

\author{
Rudi Walujo Prastianto ${ }^{1, *}$, Yoyok Setyo Hadiwidodo ${ }^{1}$, and Ibnu Fasyin Fuadi ${ }^{1}$ \\ ${ }^{1}$ Department of Ocean Engineering, Institut Teknologi Sepuluh Nopember, Kampus ITS Sukolilo \\ Surabaya 60111, Indonesia
}

\begin{abstract}
The purpose of this study is to investigate the proper Stress Concentration Factor (SCF) of a $60^{\circ}$ two-planar DKT tubular joint of a tripod wellhead offshore structure. So far, calculation of SCF for a multiplane tubular joint was based on the formulation for the simple/uniplanar tubular joints that yield in over/under prediction of the SCF of the joint. This situation in turn decreasing the accuracy of fatigue life prediction of the structures. The SCF is one of the most important parameters in the tubular joint fatigue analysis. The tubular joint is modelled as finite element models with bending loads acting on the braces that cover a wide range of dimensionless geometrical parameters $(\beta, \tau, \gamma)$. The effect of such parameters on the SCF distribution along the weld toe of braces and chord on the joint are investigated. Validation of the finite element model has shown good agreement to the global structural analysis results. The results of parametric studies show that the peak SCF mostly occurs at around crown 2 point of the outer central brace. The increase of the $\beta$ leads to decrease the SCF. While the increase of the $\tau$ and $\gamma$ leads to increase the $\mathrm{SCF}$. The effect of parameter $\beta$ and $\gamma$ on the SCF are greater than the effect of parameter $\tau$.
\end{abstract}

\section{Introduction}

Jacket platform is an offshore structure often used for oil and gas exploitation of offshore hydrocarbon reservoirs in shallow water areas, which have main structure consists of tubular members welded between braces and chords [1]. Stresses occurred at brace-tochord intersection line of the tubular joint are very complex and unevenly distributed. The ratio between the maximum stress at the intersection line and the nominal stress in the brace is called Stress Concentration Factor (SCF). The SCF is one of the important components in the calculation of fatigue damage [2].

The majority of tubular joints commonly found in offshore structures are in the form of multi-planar tubular joints. The multi-planar effect plays an important role in the stress distribution at the brace-to-chord intersection areas of the tubular joints. For such multiplanar joints, the SCF formulae of simple uni-planar tubular joints are not applicable in

* Corresponding author: rudiwp@oe.its.ac.id 
SCF prediction. The fact show that very few investigations have been reported due to the complexity and high cost involved, especially with bending loading conditions.

The significance of this study is to obtain proper SCF for a specific multi-planar double KT tubular joint. From design point of view this specific SCF would increase accuracy in fatigue life prediction for the joint itself. This research will study the effect of dimensionless geometrical parameters $(\beta, \tau$, and $\gamma)$ on the SCF distribution along the weld toe in the brace-to-chord intersection region of a multi-planar double KT tubular joint with several variations of the geometrical parameters subjected to in-plane loading at the braces. Finite element models of the tubular joint are used for local stress analysis to obtain stress distribution in the intersection region which is the accuracy obtained is strongly influenced by the numerical model to be analyzed [3].

\section{Literatures Review}

The understanding of the behaviour of completely multiplanar joints is very limited. During the past thirty years, a significant number of scientific papers and reports have been published on the study of SCFs in various uni-planar tubular joints. As a result, many parametric study in terms of the joint geometrical parameters have been proposed, providing SCF values of several uni-planar joint types for several loading conditions. Two following paragraphs briefly present the research papers on the determination of SCF distribution along the brace-to-chord intersection of uni-planar joints and on the calculation of SCFs in the multi-planar tubular joints, respectively.

Yeoh, et al. presented about behavior of tubular T-joints subjected to combined loadings [4]. Soh and Soh [5] researched about hot spot stress of K tubular joints subjected to combined loadings. Pang and Lee [6] presented three-dimensional finite element analysis of a tubular T-joint under combined axial and bending loading. Chang and Dover [7] predicted of stress distributions along intersection of tubular Y-joints and T-joints. Shao, et al. [8] predicted of hot spot stress distribution for tubular K-joint under basic loadings.

Research on the distribution of SCF on multiplanar tubular joints was done by Chiew, et al. [9], for the multiplanar tubular XX-joints. Karamos, et al. [10] derived the SCF formula and investegated stress distribution along intersection line on the multiplanar DTjoint due to the bending load. Research was also undertaken by Wingerde, et al. [11] formulating the SCF formula for uniplanar tubular joints $\mathrm{K}$ and multiplanar KK. Woghiren and Brennan [12] developed a set of parametric formulae to predict the values of SCF in multi-planar rack-stiffened tubular KK-joints. Naibaho, et al. [13] presented about SCF parametric study of multiplanar tubular KDT-joint. Puspaningtyas, et al. [14] researched about stress intensity factor parametric study of multiplanar tubular joint with fracture mechanics. Fuadi, et al. [15] derived the SCF formula for multiplanar tubular DKT-joint.

\section{Finite Element Modelling}

The structure to be analyzed in this case is a Multi-Planar Double KT tubular joint on the bracing of structure jacket platform (see Figure 1). Data used in this local analysis are structural geometry data, material properties and loading of the global analysis of structure jacket platform. The loading data is obtained from the global modeling of the structure (see Table 1 and Table 2). Chord and braces have the same material properties with the steel density and Young modulus of $563.5 \mathrm{lb} / \mathrm{ft}^{3}$ and 30,000 ksi, respectively. Yield strength and Poisson's ratio of the steel are $50 \mathrm{ksi}$ and 0.3 , respectively. 
In this multiplanar double KT tubular joint will be varied with several parameters, namely the parameters of beta $(\beta)$, tau $(\tau)$, gamma $(\gamma)$, and the angle between chord and brace $(\theta)$. The definition of each the tubular joint geometric parameters are: $\beta(=d / D)$ is ratio between diameter of brace and chord; $\tau(=\mathrm{t} / \mathrm{T})$ is ratio between wall thickness of brace and chord; $\gamma(=\mathrm{D} / 2 \mathrm{~T})$ ratio between diameter and wall thickness of chord; and $\theta$ stands for angle between chord and brace.

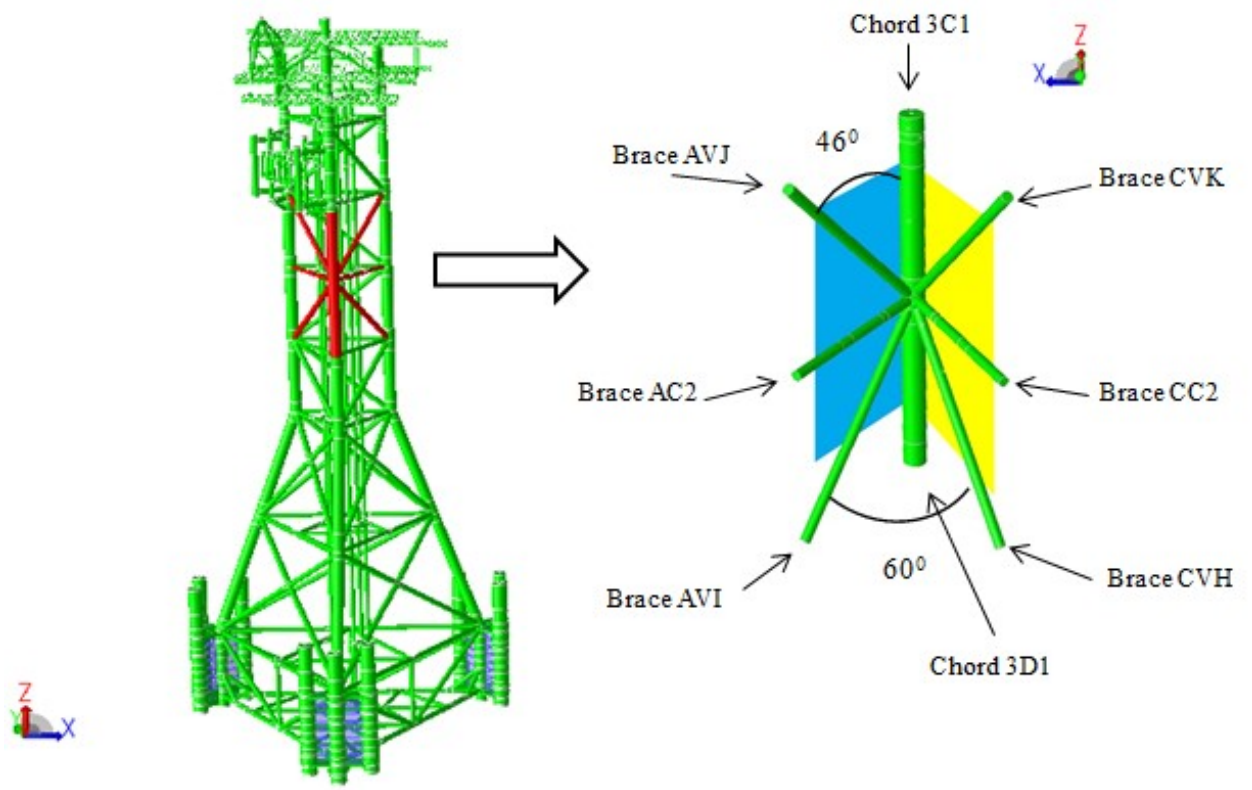

Fig. 1. A two-planar double KT (DKT) tubular joint taken from an offshore structure.

Table 1. Data of the DKT tubular joint.

\begin{tabular}{|c|c|c|c|c|}
\hline Joint Member & $\begin{array}{c}\text { Wall Thickness } \\
\text { (in) }\end{array}$ & $\begin{array}{c}\text { Outside } \\
\text { Diameter (in) }\end{array}$ & $\begin{array}{c}\text { Inside } \\
\text { Diameter } \\
\text { (in) }\end{array}$ & Length (in) \\
\hline Chord 3C1 & 2 & 54 & 50 & 312 \\
\hline Chord 3D1 & 2 & 54 & 50 & 312 \\
\hline Brace CVK & 1 & 24 & 22 & 540 \\
\hline Brace AVJ & 1 & 24 & 22 & 540 \\
\hline Brace CC2 & 1 & 24 & 22 & 384 \\
\hline Brace AC2 & 1 & 24 & 22 & 384 \\
\hline Brace CVH & 1 & 24 & 22 & 540 \\
\hline Brace AVI & 1 & 24 & 22 & 540 \\
\hline
\end{tabular}

As mentioned earlier, the aim of the present research is to study the effect of dimensionless geometrical parameters on the SCF distribution along the weld toe (on the chord side) of the main (inclined) brace. Different values assigned to each non-dimensional parameter are as follows: $\beta=0.35,0.4$, and $0.45 ; \gamma=10,12$, and $15 ; \tau=0.35,0.45$, and 0.55 . These values are selected to cover the practical range of the normalized parameters typically found in multi-planar tubular joints of offshore structures, namely: $0.3 \leq \beta \leq 0.5$; $0.3 \leq \tau \leq 0.6$; and $10 \leq \gamma \leq 14$. 
Table 2. Moments and forces on the DTK tubular joint from global analysis

\begin{tabular}{|c|c|c|c|c|c|c|}
\hline \multirow{2}{*}{ Joint Member } & \multicolumn{3}{|c|}{ Moments (kips-in) } & \multicolumn{3}{c|}{ Forces (kips) } \\
\cline { 2 - 7 } & $\mathrm{Mx}$ & $\mathrm{My}$ & $\mathrm{Mz}$ & $\mathrm{Fx}$ & $\mathrm{Fy}$ & $\mathrm{Fz}$ \\
\hline Brace CVK & -0.5 & -32.9 & -10 & -48.6 & -0.01 & -0.1 \\
\hline Brace AVJ & 2.3 & -116.6 & 12.7 & -13.5 & -0.05 & 1.4 \\
\hline Brace CC2 & 213.4 & -675.8 & -5.4 & 9.9 & 0.01 & 9.8 \\
\hline Brace AC2 & -94.6 & -384.8 & 3.7 & 10.1 & -0.01 & 5.6 \\
\hline Brace CVH & 1.2 & -42.9 & 20.5 & 49.7 & 0.04 & -0.1 \\
\hline Brace AVI & -0.68 & -186.3 & 31.4 & -13.8 & -0.11 & 1.6 \\
\hline
\end{tabular}

Multi-planar double KT tubular joint to be analyzed is modeled by using a finite element method-based software with a geometry as depicted at Figure 2. Modeling is done by using the geometry, section and material properties and loading data as presented in Table 1 and Table 2. Weld modeling is necessary because the intersection between the two tubular (brace and chord) will form intersection line, where the stress concentration occurs in the area along the intersection line. The welding size along the brace-chord intersection satisfies the AWS specifications [16].

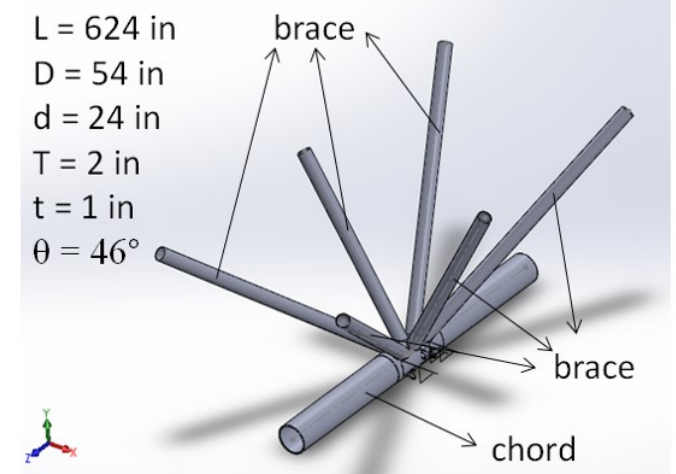

$$
\begin{aligned}
& \begin{array}{l|l|}
\alpha=21.5 & \alpha=2 \mathrm{~L} / \mathrm{D} \\
\beta=0.44 & \beta=\mathrm{d} / \mathrm{D} \\
\tau=0.5 & \tau=\mathrm{t} / \mathrm{T} \\
\gamma=13.5 & \gamma=\mathrm{D} / 2 \mathrm{~T} \\
\cline { 2 - 2 } &
\end{array} \\
& \mathrm{L}=\text { chord length } \\
& \mathrm{D}=\text { chord diameter } \\
& \mathrm{T}=\text { chord thickness } \\
& \mathrm{d}=\text { brace diameter } \\
& \mathrm{t}=\text { brace thickness } \\
& \theta=\text { angle between chord } \\
& \text { and brace (degree) }
\end{aligned}
$$

Fig. 2. Model geometry of the multi-planar DKT tubular joint for local analysis.
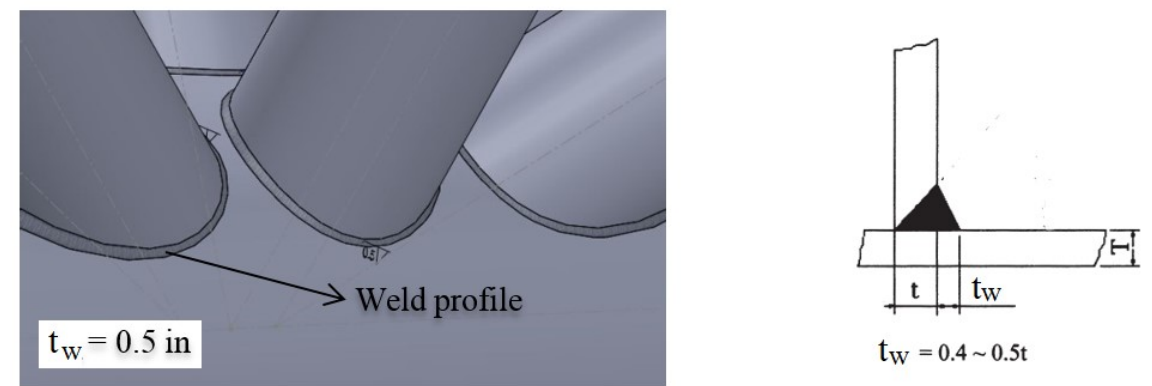

$\mathrm{t}_{\mathrm{W}}=0.4 \sim 0.5 \mathrm{t}$

(a) Weld profile on the model

(b) AWS D1.1. specifications for the weld

Fig. 3. Weld size along the brace-chord intersection satisfies the AWS specifications.

Meshing strategy for the tubular joint model is performed with meshing size is made smaller (smooth) on regions around the connection between the brace and chord. While in 
regions far from the connection area as observation areas, meshing size is made larger (coarser). The element used for the model is a solid three-dimensional element with a linear element type of tetrahedron (see Figure 4).
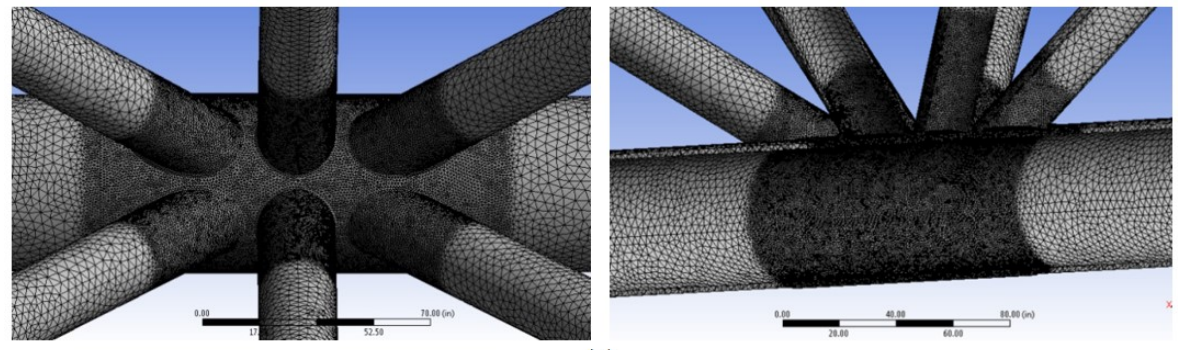

(a)

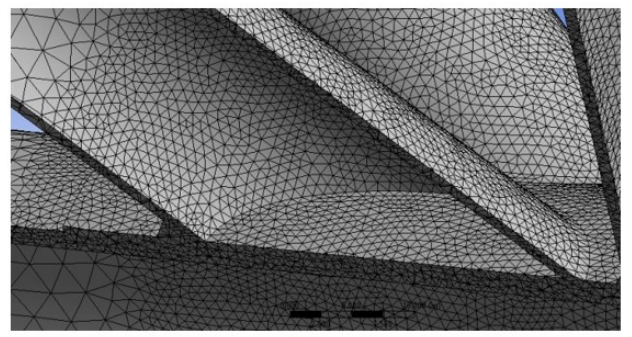

(b)

Fig. 4. Finite element model for the multiplanar DKT tubular joint: (a) Generated mesh for the tubular model, (b) Detail view of the generated mesh for the model.

The chord end fixity conditions of tubular joints in offshore structures may range from "almost fixed" to "almost pinned" with generally being closer to "almost fixed". For analysis in this study, it is assumed that all of the constraints are fixed on both ends of the chord. The tubular joint model with the parameter $\alpha>12$, the magnitude of the stress at the joint area is not affected by the boundary conditions on the chord. Therefore In this study the value of parameters $\alpha=21.5$ was assigned for all the models. The loading applied to the model are in-plane bending loading with the values obtained from the global modeling as presented in Table 2. In this study three different loading conditions (LC) are assigned to the models as can be seen in Figure 5. 


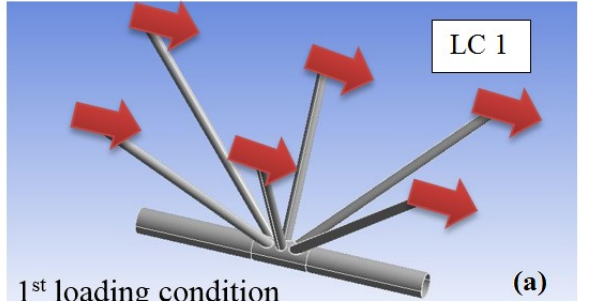

$1^{\text {st }}$ loading condition (a)

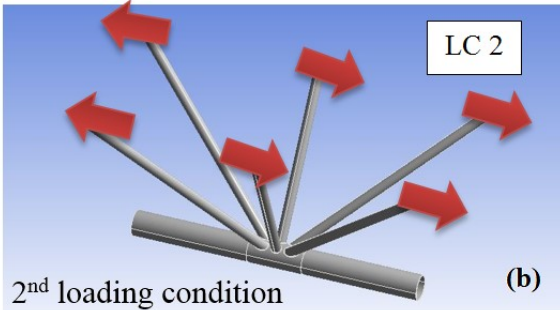

(b)

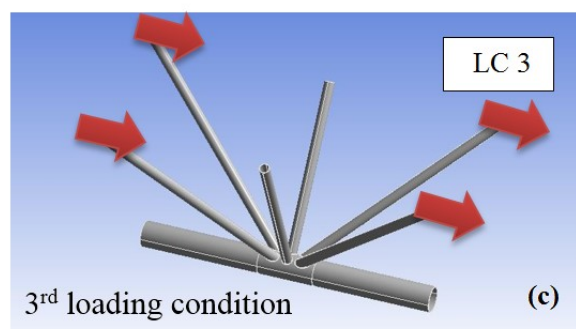

Fig. 5. Three in-plane bending (IPB) loading conditions for the model.

\subsection{Model Validation}

The meshing sensitivity analysis is performed to measure the consistency and accuracy of the results from the finite element model as a function of the number of elements used.

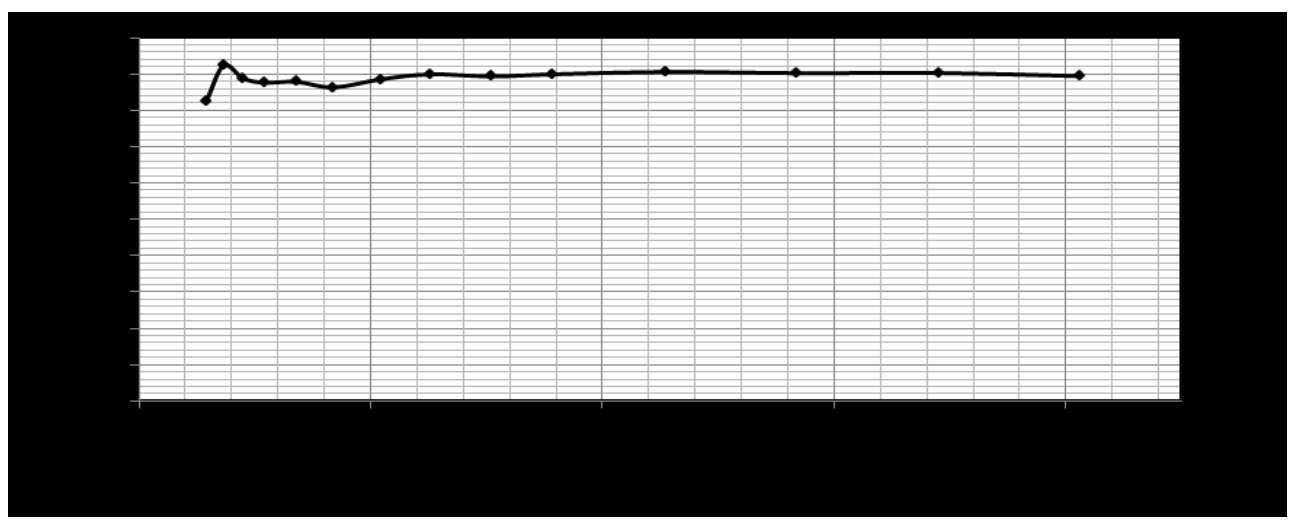

Fig. 6. Graph of meshing sensitivity analysis.

Size of meshing is changed iteratively, until the stress generated at a particular location becomes constant. From the results of meshing sensitivity test (see Figure 6), it is found that the number of meshing elements whose stress output is near constant at a particular point is meshing with the number of elements as many as 1,000,000 elements.

Table 3. Result of the meshing sensitivity test.

\begin{tabular}{|c|c|c|c|c|c|}
\hline No & $\begin{array}{c}\text { Number of } \\
\text { elements }\end{array}$ & $\begin{array}{c}\text { CPU time } \\
\text { (minute) }\end{array}$ & $\begin{array}{c}\text { Disk Storage } \\
\text { (bytes) }\end{array}$ & $\begin{array}{c}\text { Stress } \\
\text { (ksi) }\end{array}$ & $\begin{array}{c}\text { Change } \\
\text { (\%) }\end{array}$ \\
\hline 1 & 358,179 & 10 & $1,168,567,338$ & 8.261 & \\
\hline 2 & 373,059 & 10.2 & $1,179,997,513$ & 9.235 & 10.547 \\
\hline 3 & 390,022 & 10.3 & $1,195,417,876$ & 8.877 & 4.037 \\
\hline 4 & 408,545 & 10.5 & $1,205,657,858$ & 8.763 & 1.301 \\
\hline
\end{tabular}




\begin{tabular}{|c|c|c|c|c|c|}
\hline 5 & 435,671 & 10.8 & $1,217,451,712$ & 8.788 & 0.284 \\
\hline 6 & 467,794 & 11.3 & $1,220,329,118$ & 8.633 & 1.795 \\
\hline 7 & 509,145 & 11.7 & $1,239,971,901$ & 8.859 & 2.551 \\
\hline 8 & 551,325 & 12.1 & $1,245,735,142$ & 8.992 & 1.479 \\
\hline 9 & 603,822 & 12.6 & $1,250,661,018$ & 8.933 & 0.660 \\
\hline 10 & 656,583 & 13 & $1,260,421,134$ & 8.991 & 0.645 \\
\hline 11 & 754,722 & 13.6 & $1,277,445,914$ & 9.058 & 0.740 \\
\hline 12 & 867,228 & 14.1 & $1,282,657,781$ & 9.025 & 0.366 \\
\hline 13 & 990,615 & 14.7 & $1,295,957,708$ & 9.029 & 0044 \\
\hline 14 & $1,111,926$ & 15.5 & $1,311,581,327$ & 8.942 & 0.973 \\
\hline
\end{tabular}

Another way to validate the results of the local analysis for the model is to compare it with the global model in term of the nominal stress in the brace using Von Mises stress, as presented at Table 4. From Table 4 it is shown that the difference for both analysis is very small (less than 1\%), indicating that the model for local analysis was accurate in terms of proper structural modeling, loading, boundary conditions applied and also the results of the analysis.

Table 4. Nominal Stress validation.

\begin{tabular}{|c|c|c|}
\hline \multicolumn{2}{|c|}{$\boldsymbol{\sigma}_{\text {N.Von Mises }}(\mathbf{k s i})$} & \multirow{2}{*}{$\begin{array}{c}\text { Error } \\
\text { (\%) }\end{array}$} \\
$\begin{array}{c}\text { FEA } \\
\text { (Global model) }\end{array}$ & $\begin{array}{c}\text { FEA } \\
\text { (Local model) }\end{array}$ & \\
\hline 9.0297 & 9.0298 & 0.000916 \\
\hline
\end{tabular}

\subsection{Hot-spot Stress and SCF Calculation}

The widely accepted conventional approach for fatigue strength assessment of tubular joints is to use the geometric stresses at the weld toe. According to DNVGL-RP-C203 [17] hotspot stress determined using linear extrapolation. The linear extrapolation method is done by making two points forming an area which will be extrapolated in linear stress. In this study, to determine the distance of two linear extrapolation points used refers to DNVGLRP-C203 (see Figure 7). The maximum principal stress is used as linear extrapolation to determine the hot-spot stress [18].

After the known nominal stress and hot-spot stress, the formula stress concentration factor is:

$$
S C F=\frac{\sigma_{m a k s}}{\sigma_{n}}
$$




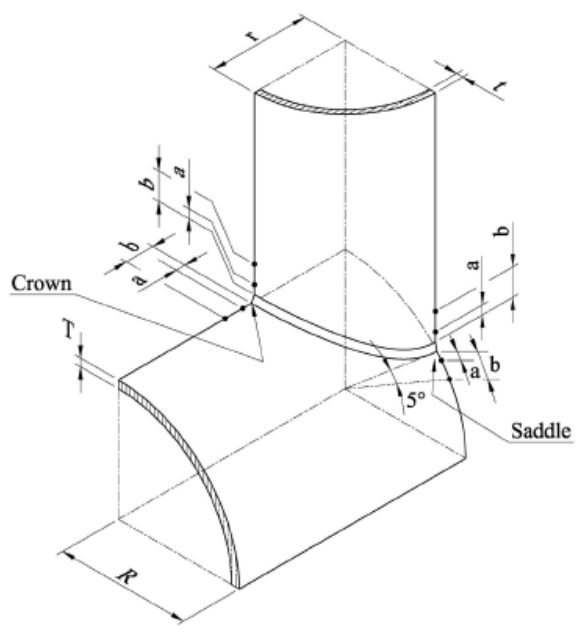

Fig. 7. Extrapolation procedure recommended by DNVGL-RP-C203.

\section{Results and Discussion}

The result of the parametric study with finite element approach is performed to determine the effect of the non-dimensional parameter variation on the stress distribution along the intersection line between the brace and the chord, which in present study is done along the weld toe on the chord side. Stress distribution along the weld toe on the chord side to be investigated only on the joint between the brace and the chord that experienced the greatest stress.

In this study, a brace of the DKT that experienced the greatest stress due to the in-plane bending loading is one of the central braces (the CC2 brace) as can be seen in Figures 8 and 9. It is very important to obtain stress distribution (then presented as SCF distribution) along the brace-chord intersection line of the observed brace. It was used 8 points to describe SCF distribution along the intersection line (see Figure 10) with interval of $45^{\circ}$. Point 1 (as Crown 1 point) is started at a position of an angle of $0^{\circ}$, the second and other next points are located at every next increment of $45^{\circ}$ in clockwise direction. The Point 3,5 and 7 is then called as Outer Saddle point (at $90^{\circ}$ ), Crown 2 point (at $180^{\circ}$ ), and Inner Saddle (at $270^{\circ}$ ), respectively.

To evaluate effects of the dimensionless geometrical parameters on the SCF distribution at the weld toe (on the chord side) along the intersection line of the main (central) brace, different values are assigned to each non-dimensional parameter, namely $\beta=0.35, \beta=0.4$, and $\beta=0.45 ; \gamma=10, \gamma=12$, and $\gamma=15$; and $\tau=0.35, \tau=0.45$, and $\tau=0.55$. 


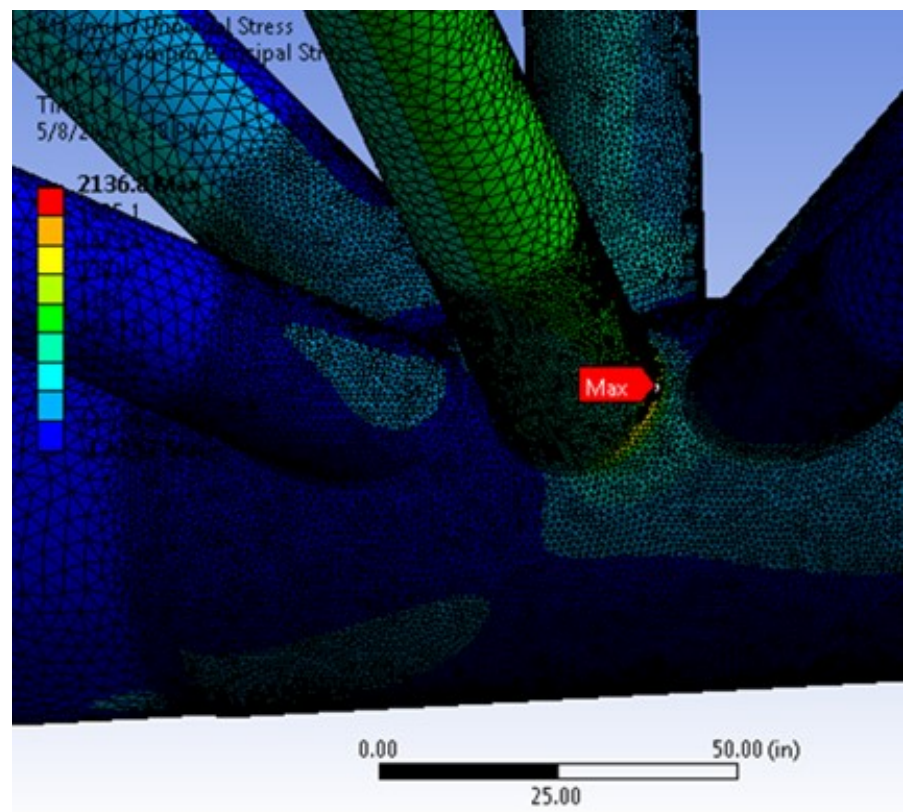

Fig. 8. Maximum stress occurs at the central brace-CC2.

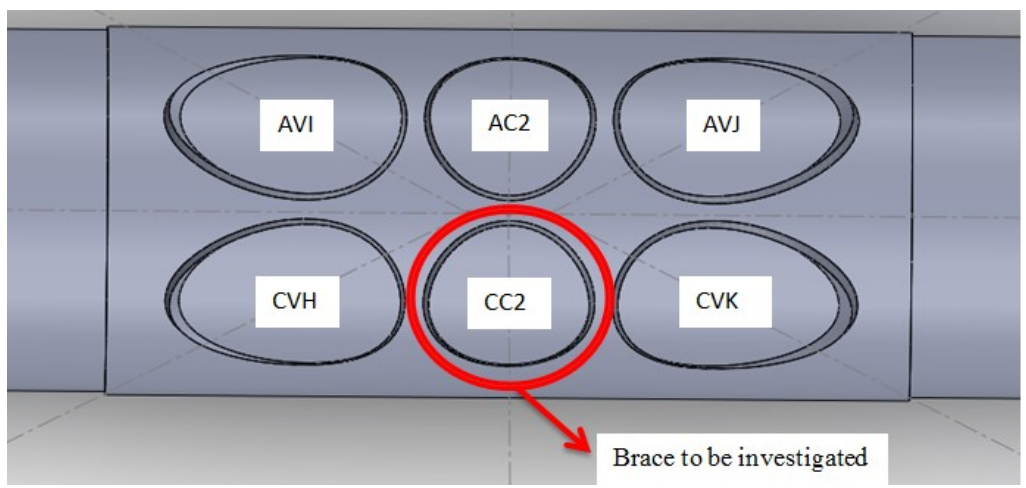

Fig. 9. Location of the central brace-CC2 to be investigated.

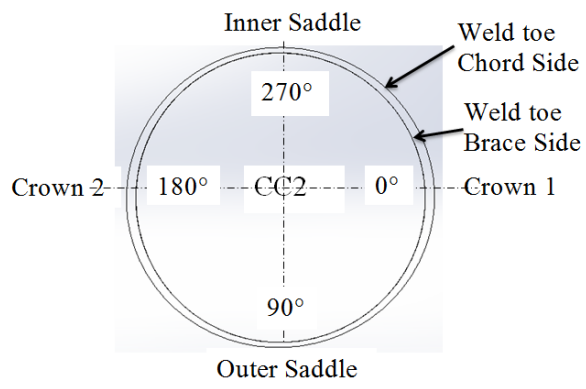

Fig. 10. Observed positions in the brace-chord intersection line of the central brace of the model. 


\subsection{Effect of $\beta$ on the SCF Distribution}

The parameter $\beta$ is a ratio of the brace to chord diameter. In this study, there are three models with different of $\beta$ for each model, i.e. $\beta=0.35, \beta=0.4$ and $\beta=0.45$, respectively. Increase of the $\beta$ in the models having constant value of chord diameter leads to increase the brace diameter. All parameters except the $\beta$ parameter, i.e., the parameters $\tau, \gamma$ and $\theta$ are made equal for the three models $\left(\tau=0.5, \gamma=13.5\right.$, and $\left.\theta=46^{\circ}\right)$.

Figure 11 shows results of SCF distribution due to three different load conditions. For all applied in-plane bending (IPB) load conditions, the peak SCF majority occurs in the area around the point of crown 2. For the case of IPB-LC 1 the peak SCF occurs almost precisely in crown 2 point for all $\beta$ values. But two SCF peaks appeared at positions of around $135^{\circ}$ and $225^{\circ}$ for $\beta=0.35$ at the case of IPB-LC 2 . Very different pattern of SCF distribution along the brace-chord intersection line occurred for the case of IPB-LC 3 rather than the two previous loading conditions. For the latter case, two peaks of SCF appeared which is the first peak occurred at $135^{\circ}$ and the second at $225^{\circ}$ for all three $\beta$ values. For smaller $\beta$, the difference between two peaks of the SCF becomes much larger.
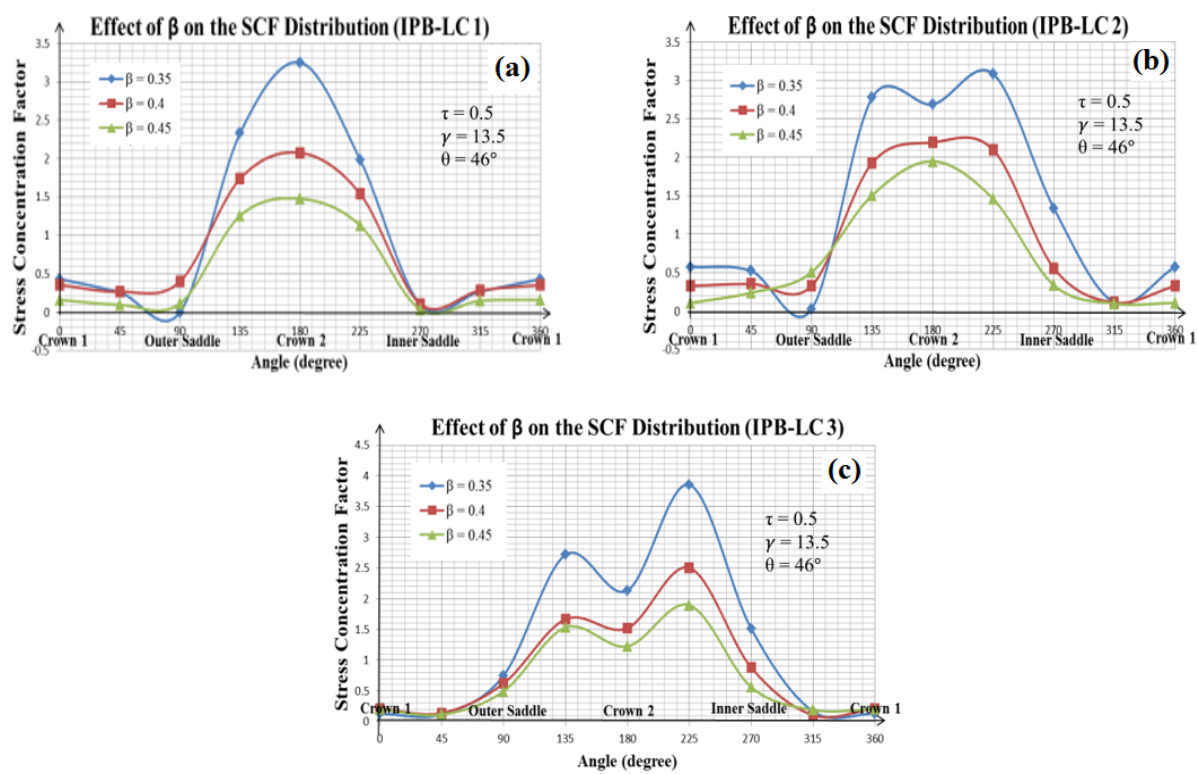

Fig. 11. Effect of $\beta$ on the SCF distribution due to in-plane bending loading for three different load conditions (LC 1, LC 2, and LC 3).

Generally, results of the investigation indicate that increase of the $\beta$ leads to decrease SCF around the Crown 2 area along the weld toe (on the chord side) at the brace-chord intersection line. The largest SCF of about 4 occurred at position of $225^{\circ}$ for the $\beta=0.35$ at the case of IPB-LC 3.

\subsection{Effect of $\gamma$ on the SCF Distribution}

The parameter $\gamma$ is the ratio of diameter or radius to wall thickness of the chord. In this study, there are three models with different of $\gamma$ for each model, i.e. $\gamma=10, \gamma=12$ and $\gamma=$ 15. Increase of $\gamma$ in the models having constant value of chord diameter leads to decrease the chord wall thickness. All parameters except the $\gamma$ parameter, i.e., the parameters $\beta, \tau$ and $\theta$ are made equal for the three models $\left(\beta=0.44, \tau=0.5\right.$, and $\left.\theta=46^{\circ}\right)$. 
Result of investigation can be seen in Figure 12 which is opposite to the $\beta$ effect previously described, that increase of the $\gamma$ leads to also increase SCF distribution along the brace-chord intersection line. Although the all load conditions caused the peak SCF majority occurs in the area around the point of crown 2 , but each load condition yielded different SCF peaks at the range of $135^{\circ}$ to $225^{\circ}$.

The peak SCF occurs almost precisely in crown 2 point $\left(180^{\circ}\right)$ for all $\gamma$ values for the case of IPB-LC 2. For the case of IPB-LC 1 and LC 3, two SCF peaks appeared at positions of around $135^{\circ}$ and $225^{\circ}$ for all $\gamma$. For the previous case of loading, the first SCF peak (at $135^{\circ}$ ) is slightly larger than the second one (at $225^{\circ}$ ) for all three $\gamma$ values. Meanwhile, for the latter case, the second SCF peak (at $225^{\circ}$ ) drastically became larger as $\gamma$ increase. Generally, the smallest SCF of about less than 1.6 occurred at the range of $135^{\circ}$ to $225^{\circ}$ for all $\gamma$ values at the case of IPB-LC 1 .
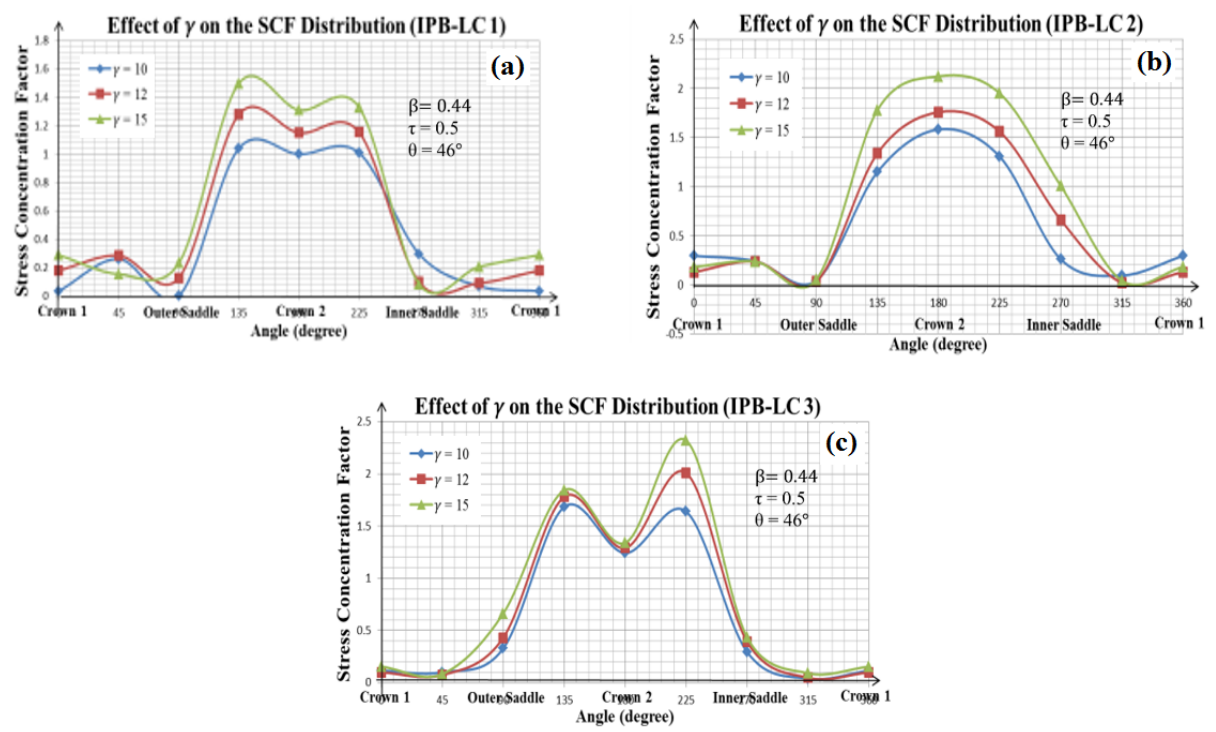

Fig. 12. Effect of $\gamma$ on the SCF distribution due to in-plane bending loading: (a) Case of IPB-LC 1, (b) Case of IPB-LC 2, and (c) Case of IPB-LC 3.

\subsection{Effect of $\tau$ on the SCF Distribution}

The parameter $\tau$ is the ratio of brace to chord wall thickness. In this study, three models are used with different of $\tau$ for each model, i.e. $\tau=0.35, \tau=0.45$ and $\tau=0.55$. Increase of $\tau$ in the models having constant value of chord wall thickness leads to increase of brace wall thickness. All parameters except the $\tau$ parameter, i.e., the parameters $\beta, \gamma$ and $\theta$ are made equal to the three models $\left(\beta=0.44, \gamma=13.5\right.$, and $\left.\theta=46^{\circ}\right)$.

As can be seen in Figure 13, effect of $\tau$ on the SCF distribution along the brace-chord intersection line almost similar to the $\gamma$ effect previously described in terms of magnitude and pattern of the SCF distribution. Increase of the $\tau$ leads to also increase SCF, especially at the position range of $135^{\circ}$ to $225^{\circ}$ for all cases of IPB loading conditions.

Meanwhile, variation of the $\tau$ caused almost only slight changes to the SCF even though in the area around the point of crown 2 (at the range of $135^{\circ}$ to $225^{\circ}$ ) for each load condition. The $\tau$ variation was not sensitive to the change of the SCF distribution along the brace-chord intersection line rather than the previous two parameters of $\beta$ and $\gamma$. 

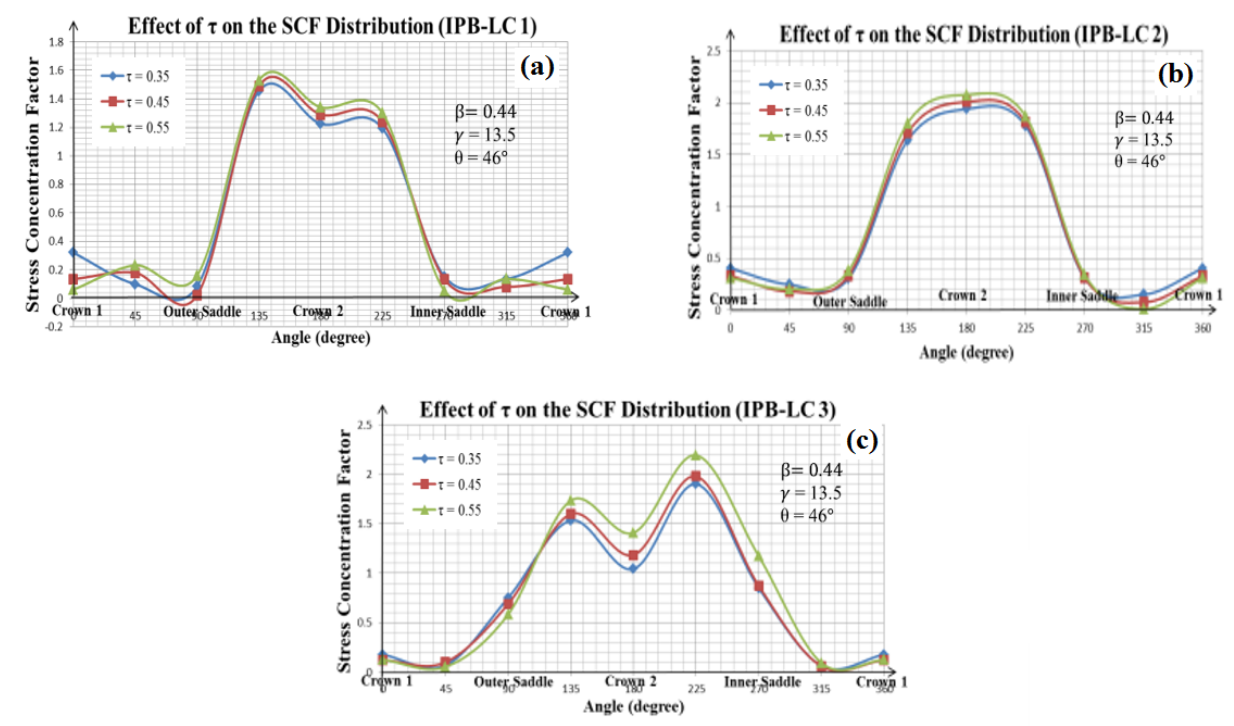

Fig. 13. Effect of $\tau$ on the SCF distribution due to in-plane bending loading: (a) Case of IPB-LC 1, (b) Case of IPB-LC 2, and (c) Case of IPB-LC 3.

\section{Conclusions}

Conclusions can be drawn from the present study are as follow:

- The results of parametric studies show that the peak SCFs mostly occurs at around Crown 2 point of the outer central brace at positions of around $135^{\circ}$ and $225^{\circ}$ for all three IPB loading conditions.

- The increase of the $\beta$ leads to decrease the SCF. While the increase of the $\tau$ and $\gamma$ leads to increase the SCF.

- The effect of parameter $\beta$ and $\gamma$ on the SCF distribution along the brace-chord intersection line are greater than the parameter $\tau$ even though in the area around the Crown 2 (at the range of $135^{\circ}$ to $225^{\circ}$ ) for all three load conditions.

The authors wish to thank Institute for Research and Community Services (LPPM), Institut Teknologi Sepuluh Nopember (ITS) Surabaya for the financial support through a research grant scheme of "Laboratory Research 2017".

\section{References}

1. Ahmadi, Hamid, E. Zavvar. Stress concentration factors induced by out-of-plane bending loads in ring-stiffened tubular KT-joints of jacket structures, Thin Walled Structures, Vol. 91, 82-95, (2015)

2. U. Hidayat, R.W. Prastianto, W. Wardhana. SCF parametric study of multiplanar tubular joint double K. Bachelor Thesis of Ocean Engineering Department FTK-ITS. Surabaya. (2016)

3. D.S. Murthy. An Efficient FE Modelling Strategy for Fracture Analysis of Tubular 
Joints. Journal Structural Engineering Research Centre, Vol. 85, May, (2004)

4. Yeoh, Seng-Keat, Ai-Kah Soh and Chee-Kiong Soh. Behavior of Tubular T-Joints Subjected to Combined Loadings. Journal Construction Steel Research, Vol. 32, 259280, (1995)

5. Soh, Ai-Kah, Chee-Kiong Soh. Hot Spot Stress of K Tubular Joints Subjected to Combined Loadings. Journal Construction Steel Research, Vol. 26, 125-140, (1993)

6. H.L.J. Pang, C.W. Lee. Three-dimensional finite element analysis of a tubular T-joint under combined axial and bending loading. Journal Fatigue, Vol. 17, 313-320, (1995)

7. E. Chang, W.D. Dover. Predicted of stress distributions along intersection of tubular Y-joints and T-joints. International Journal of Fatigue, Vol. 21, 361-381, (1999)

8. Young-Bo, Shao, Du Zhi-Fu, Lie Seng-Tjhen. Predicted of hot spot stress distribution for tubular K-joint under basic loadings. Journal of Construction Steel Research, Vol. 65. 2011-2026, (2009)

9. S.P. Chiew, C.K. Soh, N.W. Wu. General SCF design equations for steel multiplanar tubular XX-joints. International Journal of Fatigue, Vol. 22, 283-293, (2000)

10. Karamos, A. Spyros, A. Romejin, J. Wardenier. SCF equations in multi-planar welded tubular DT-joint including bending effects. Marine Structures, Vol. 15, 157-173, (2002)

11. Wingerde, A.M. Van, J.A. Packer, J. Wardenier. Simplified SCF formulae and graphs for CHS and RHS K- and KK-connections. Journal of Construction Steel Research, Vol. 57. 221-252, (2001)

12. C.O. Woghiren, F.P. Brennan. Weld toe stress concentrations in multi-planar stiffened tubular KK-joints. International Journal of Fatigue, Vol. 31, 164-172, (2009)

13. B. Naibaho, R.W. Prastianto, W. Wardhana. SCF parametric study of multiplanar tubular KDT-joint. Bachelor Thesis of Ocean Engineering Department FTK-ITS. Surabaya, (2016)

14. A. Puspaningtyas, R.W. Prastianto, W. Wardhana. Parametric study of stress intensity factor on multiplanar tubular joint with fracture mechanics. Bachelor Thesis of Ocean Engineering Department FTK-ITS. Surabaya, (2016)

15. I.F. Fuadi, R.W. Prastianto, N. Syahroni. Formulation of stress concentration factors for multiplanar tubular DKT-joint using finite element method. Bachelor Thesis of Ocean Engineering Department FTK-ITS. Surabaya, (2017)

16. Structural welding code: AWS D 1.1. USA, American Welding Society (AWS), (2002)

17. DNVGL RP-C203. Recommended Practice, Fatigue Strength Analysis of Offshore Steel Structure, (2001)

18. M. Haghpanahi, H. Pirali. Hot Spot Stress Determination for a Tubular T-Joint under Combined Axial and Bending Loading. International Journal of Engineering Sciences, Vol. 17, 21-28, (2006) 